\title{
Lächeln im Mondlicht
}

\section{Rolf Gerber}

Dr. med., Facharzt für Psychiatrie und Psychotherapie, FMH

«Hostettler, Kantonspolizei», meldet sich eine aufgeregte Stimme am Telefon. «In der Asylunterkunft ist eine Person am Randalieren. Bitte kommen Sie so schnell wie möglich.»

Jorge hatte bereits geschlafen. Rasch zieht er sich Hose, Hemd und Jacke über das Pyjama, greift nach dem Notfallkoffer und fährt mit dem Lift in die Tiefgarage. Hugentobler, der Besitzer der Dachwohnung, hatte wieder einmal Zigarren im Lift geraucht. Im neuen koreanischen Kompakt SUV, den Jorge sich zum 55. Geburtstag geleistet hatte, riecht es angenehm nach neuem Leder und dem Parfüm seiner Frau. Freundlich wird er vom Bordcomputer begrüsst. Auf der Garagenausfahrt sieht er im hellen Mondlicht auf dem Asphalt die Kreidenmalereien der Nachbarskinder. Wenig später trifft er im Asylbewerberheim ein. Die Polizei scheint noch nicht

\section{Er wirkt abwesend, murmelt Formeln vor sich hin und verstreut sorgfältig Papierschnitzel.}

da zu sein. Auf dem Gang sieht Jorge einen etwa 25-jährigen Mann mit asiatischen Gesichtszügen. Er wirkt abwesend, murmelt Formeln vor sich hin und verstreut sorgfältig Papierschnitzel. Jorge nickt ihm zu. Keine Reaktion. Eine verängstigte Frau mit zwei Kleinkindern auf den Armen deutet mit dem Kopf in Richtung des Büros. Der Betreuer, selbst Asylbewerber und aktuell im Status des vorläufig Aufgenommenen, informiert ihn. Es handle sich um einen jungen Mann aus Afghanistan, der alleine eingereist sei. Bereits vor einigen Wochen sei er via Notfallarzt von der Polizei in die Klinik gebracht worden. Die Akten seien im Hauptbüro, das für ihn aber nicht zugänglich sei. Er sei nur Hilfskraft und könne sich dadurch das Taschengeld aufbessern. Der Afghane konsumiere auch Kokain. Bis vor einer halben Stunde sei es zu Auseinandersetzungen mit anderen Bewohnern gekommen, weil er deren Schlafräume betreten habe. Aktuell agiere er im Gang und in den Gemeinschaftsräumen, die Situation habe sich etwas beruhigt. Um die Lage auch bei einer eventuell entstehenden erneuten Eskalation rasch wieder stabilisieren zu können, schlägt Jorge vor, auf das Eintreffen der Polizei zu warten. Der Betreuer zeigt ihm eine Medikamentenschachtel. Diese Tabletten seien dem Afghanen beim letzten Klinikaufenthalt verschrieben worden. Ob er sie auch einnehme, wisse er nicht. «Zyprexa, ein Medikament gegen Wahnvorstellungen», erläutert Jorge. Er selbst sei seit drei Jahren ohne definitiven Entscheid der Behörden und ohne Arbeitserlaubnis hier, erwidert der Betreuer. «Kennen Sie Israel?» Jorge bejaht. «Das Land heisst Palästina, ich bin aus Jaffa geflüchtet. Die Schweiz macht einfach nicht vorwärts mit meinem Gesuch. Hier bekomme ich nur ein Taschengeld, Überstunden werden nicht bezahlt und ich habe seit zwei Stunden eigentlich Feierabend. In Palästina habe ich Betriebswirtschaft studiert. Hier darf ich nicht einmal einfache Bürotätigkeiten verrichten. Finden Sie das vernünftig?» Jorge zeigt Verständnis, hat aber keine Lust, sich auf politische Diskussionen einzulassen. «Ich telefoniere kurz mit dem Dienstarzt der Klinik, um weitere Informationen zu erhalten Die Entlassung sei erst vor zwei Wochen erfolgt. Der Patient habe unter Kokaineinfluss psychotisches Verhalten gezeigt. Unter Drogenabstinenz und neuroleptischer Medikation sei es ihm nach wenigen Tagen wieder besser gegangen. Jorge schildert die aktuelle Situation und kündigt die Zuweisung an. Er werde versuchen, mit dem Afghanen zu sprechen. Wahrscheinlich sei eine Einweisung aber unvermeidbar. Zwischenzeitlich ist die zweiköpfige, gemischtgeschlechtliche Polizeipatrouille eingetroffen. Jorge schildert die Situation und schlägt vor, dass die Polizisten wachsam im Hintergrund bleiben sollen. Er werde mit dem Afghanen sprechen und ihm die erneute Hospitalisation vorschlagen. Vom Betreuer erfährt Jorge, dass der Afghane etwas Englisch verstehe. «What are you doing?», beginnt Jorge das Gespräch. Keine Antwort. Der Afghane schaut ihn nur kurz verwirrt an und fährt fort, aus einem Schuhkarton Papierschnitzel zu streuen. Dabei murmelt er Formeln in einer für Jorge unverständlichen Sprache. «What are you doing?», fragt Jorge erneut. Diesmal schaut der Afghane mit starrem, angsterfüllten Blick auf Jorge und wirkt angespannt. Sein Ritual unterbricht er nur kurz. Jorge schaut zwei Minuten zu. Die rituelle Aktion scheint den Afghanen zu beruhigen. «Good job, good job ... here it's ok, you did a good job ... you have to go to the hospital now", sagte Jorge mit ruhiger, aber bestimmter Stimme. «The nice people in uniforms behind me will bring you there by car. You can continue your job there. It's necessary. They definitely need it too.» 
Die Polizistin lächelt und nickt bestätigend. Sie hebt das hinuntergefallene Zigarettenpäckchen auf und gibt es dem Afghanen. Widerstandslos folgt er der Polizistin und Jorge zum Einsatzwagen. Der zweite Polizist geht mit zwei Meter Abstand hinter den dreien her und schliesst die Prozession ab. Hastig muss Jorge noch das Formular "fürsorgerische Unterbringung» ausfüllen. Name, aktuelle Situation, Einweisungsgrund, Selbstoder Fremdgefährdung, Angehörige informiert?, Formularskopie an den Betroffenen ausgehändigt? Wenn nein, warum nicht? ...

Auch die Polizei wünscht eine Kopie. Das Original ist für die Klinik bestimmt ... Der Kopierer ist natürlich in dem für den Betreuer nicht zugänglichem Büro ... Jorge arbeitet mit Durchschlagspapier, das ständig verrutscht ... im Hinterkopf hört er die Kritik, die auf der Behörde, der als Rekursinstanz ebenfalls ein Exemplar zugesandt werden muss, am Montagmorgen um kurz nach 08.00 Uhr ertönen wird ... «Formular nur teilweise ausgefüllt ... Befund unvollständig ... rechtliches Gehör vernachlässigt ... Sauschrift ... wenn alle so arbeiten würden ...» Beim Auto angekommen, öffnet der Afghane ohne Aufforderung die hintere rechte Türe und will einsteigen. «Er weiss, wie's geht, scheint nicht das erste Mal zu sein", sagt die Polizistin und wieder huscht ein sympathisches Lächeln über ihr Gesicht. Im Mondlicht sieht Jorge auf beiden Wangen zwei Grübchen sich bilden. Bis zur Kreuzung folgt Jorge dem Polizeifahrzeug, dann muss er links abbiegen. Es beginnt heftig zu regnen. Jorge verspürt ein wohliges Gefühl der Zufriedenheit. Gleichzeitig ahnt er, dass der Afghane nach Rückkehr ins Asylbewerberheim wahrscheinlich wieder Kokain dem Medikament vorziehen wird und die Kollegin oder der Kollege, der dann Dienst hat, gerufen werden wird. Die Malereien auf dem Asphalt der Garageneinfahrt sind vom Regen verwischt. Im Lift riecht es immer noch nach abgestandenem Zigarrenrauch. Ohne Licht zu machen geht Jorge in die Küche. Im Kühlschrank hat es noch Lachsreste. Gerne hätte er ein Glas Weisswein dazu getrunken ... aber eben ... Dienst ist Dienst. Jorge greift zum Mineralwasser. Leise betritt er das Schlafzimmer. In der Morgendämmerung blitzt das nackte linke Bein seiner Frau auf, das sie zur Temperaturregulation unter der Decke hervorstreckt. Das Diensthandy legt er griffbereit auf den Nachttisch, daneben Kugelschreiber und Papier.

Als er Monate später am TV die Nachrichten sieht, traut er seinen Augen nicht. In einem Bericht wird der Afghane erwähnt, wie er im Heimatland Papierschnitzel streut. Wo immer er dies tut, beginnen die Menschen zu lächeln. Um den Effekt grossflächig zu nutzen, wird er von der Armee mit Helikoptern unterstützt. Die Polizistin wird zur Vorsitzenden der Bewegung «Lächeln für den Frieden» gewählt. Der Afghane zu deren Ehrenpräsidenten. Nach dem Erfolg seiner Friedensbemühungen konnte er ins Heimatland zurückkehren. Die Polizistin folgte ihm nach. Die Uno versuchte das Konzept auf andere Weltgegenden zu übertragen. Zwei Jahre nach Jorges Notfalleinsatz wurde die Bewegung für den Nobelpreis nominiert und gewann. Zur Verleihung des Friedensnobelpreises wurde auch Jorge eingeladen. Gästekategorie 3, Zulassung zum Buffet, Kontakt mit Prominenz nach bestandener Sicherheitsprüfung erlaubt ... hinteres Sitzreihendrittel bei der Laudatio.

Das Buffet war grandios. Lachs, geräucherte Forelle, getrocknetes Elchfleisch, und und und ... vor allem aber hervorragender Weisswein, wie ihn auch das schwedische Königshaus trinkt. Schon in der Nase ein unübertreffliches fruchtiges Bouquet, Jorge tippt auf Muskattrauben in einer Assemblage mit kleinem Gewürztramineranteil. Auch frühere Preisträger sind anwesend. Jorge steht plötzlich dicht bei Obama und erschrickt. Obama lacht freundlich. Jorge stammelt verlegen «you did a good job». Obama wird von Königin Silvia von Schweden angesprochen (oder war es Soraya, Jorge kannte sich schlecht aus, seine Frau war nicht eingeladen worden). Fanfaren ertönen als Zeichen, dass die Ehrengäste den Festsaal betreten sollen und in Kürze die Feier beginnt. Das Königspaar, die Obamas (seine Frau wurde eingeladen) und weitere Preisträger schreiten voran. Der Ablauf ist bis ins kleinste Detail geplant und gleicht einem Ritual. Für die Kategorie-2und-3-Gäste gibts laut Informationsschreiben ein besonderes akustisches Signal, davor dürfen sie den Saal nicht betreten. Beim Ausleihen des vorgeschriebenen Frackes wurde es den Gästen vorgespielt. Jorge hat es sehr schrill in Erinnerung. Als er sich zum Betreten des Saales bereit macht, sieht er in der vordersten Reihe die Polizistin. Ihr Lächeln überstrahlt den gesamten Adel der Welt. Nur die Obamas können annähernd mithalten. Jorge schnappt sich noch ein Stück Lachs vom Buffet. Die Glocke schrillt und schrillt.

Im Halbschlaf greift Jorge zum Handy und hört eine Stimme sagen: «Hostettler, Kantonspolizei». 